\title{
Experiences of Mothers of Premature Infants Receiving Rehabilitation Therapy
}

\author{
Hyun-Ju Kang \\ College of Nursing, Kangwon National University, Chuncheon, Korea
}

Purpose: The purpose of this study was to explore and develop a deeper understanding of the experiences of mothers of premature children receiving rehabilitation therapy. Methods: The participants were 12 mothers with premature children who had received rehabilitation therapy for over 1 year. Individual in-depth interviews were conducted from July to August 2017. The data were analyzed through the phenomenological research method. Results: The participants' experience was structured into five thematic clusters: 'Regret and guilt that premature birth led to rehabilitation therapy', 'Burden of life in an endless tunnel', 'Changes in personal relationships surrounding me and my child', 'Meaning of new life through my child', and 'Desire to expand the rehabilitation of premature infants'. Conclusion: The results of this study will be helpful for developing family-centered care programs for premature infants at high risk of developmental disorders.

Key words: Premature infant, Rehabilitation, Mothers, Qualitative research

\section{Corresponding author Hyun-Ju Kang https://orcid.org/0000-0002-2129-1658 \\ College of Nursing, Kangwon National University, 1 Gangwondaehak-gil, Chuncheon 24341, Korea \\ TEL +82-33-250-8878 FAX +82-33-259-5636 \\ E-MAIL hjkang@kangwon.ac.kr}

*This study was supported by a 2017 Research Grant from Kangwon National University (520170027).

Received Jun 6, 2018 Revised Jun 25, 2018 Accepted Jun 25, 2018 (a) This is an Open Access article distributed under the terms of the Creative Commons Attribution NonCommercial License (http://creativecommons.org/licenses/by-nc/4.0/) which permits unrestricted noncommercial use, distribution, and reproduction in any medium, provided the original work is properly cited.

\section{INTRODUCTION}

In 2016, the crude birth rate in South Korea was 7.9\% and the total fertility rate was 1.17 . South Korea remains an extremely low birth rate country, and the premature birth rate increased by 1.5 times to $7.2 \%$ of the total number of births [1]. Major breakthroughs in neonatal intensive care technology increased the survival rate of very low birth weight infants (under $1.5 \mathrm{~kg}$ ) from $77.5 \%$ in 2002 to $85.7 \%$ in 2009 , as well as the survival rate of extremely low birth weight infants (under $1 \mathrm{~kg}$ ) from $56.1 \%$ in 2002 to $71.8 \%$ in 2009 [2,3]. However, premature infants are at a higher risk of developmental disabilities, including cerebral palsy, attention-deficit/hyperactivity disorder, vision and hearing loss, cognitive disabilities, hearing disabilities, language disorders, and neuro-movement disorders than full-term infants, and premature infants with a low gestational age and brain lesions are at a particularly high risk of developmental disabilities [4,5]. Furthermore, in extremely low birth weight infants, the incidence of intraventricular hemorrhage, which is one of the primary factors determining the prognosis for neurodevelopment, was reported to be $17.6 \%$ in a recent study; this is a similar level to the rates of 15 23\% reported in the 1990s [6,7]. Thus, the higher survival rate of premature infants, including extremely low birth weight infants, means that increasingly many children are at a high risk for developmental disabilities. Therefore, after being discharged from the neonatal intensive care unit, premature 
infants who are at a high risk for developmental disabilities or have been diagnosed with developmental disabilities receive pediatric rehabilitation treatment, including physical therapy, kinesiotherapy, occupational therapy, and speech therapy to improve their physical, sensory, cognitive, and social development indicators [8].

Premature infants are separated from their parents for a long period of time, since a premature birth is an unexpected event for the mother, and most premature infants receive inpatient treatment in the neonatal intensive care unit (NICU). Moreover, although premature infants are discharged from the NICU after treatment, the parents' burden of parenting and stress increase as the infant is likely to have a very low weight or many health problems [9]. In fact, in comparison to mothers of full-term infants, mothers of premature infants are at a higher risk of postpartum depression, because they face heavy emotional and socioeconomic burdens and higher levels of parenting-related stress [10,11]. In particular, mothers of premature infants with disabilities have been found to have a greater degree of burden, parenting stress, and depression than mothers of premature infants with no disabilities [12-14]. In addition, the development of premature infants is affected not only by physiological characteristics, but also by the parents' characteristics and home environment, including the mother's mental health and the parenting environment over a long-term period [15]. For this reason, providing adequate support and resources for the primary caregiver-the mother-should be considered to promote the optimal development of premature infants. Above all, the experiences of mothers and premature infants with developmental disabilities need to be understood in depth for precisely-targeted interventions to be developed.

Premature birth itself, and the subsequent parenting experience, are empirically unique phenomena. Thus, qualitative research has been conducted to expand the understanding of the experiences of mothers of premature infants. Nonetheless, previous research on mothers has only included studies of the general experiences of mothers, the duration of hospitalization of the premature infants, or the immediate parenting experience after the infant's discharge without considering the premature infants' developmental characteristics; hence, it is difficult to find published studies specifically focusing on the experiences of mothers in Korea with a premature infant with potential developmental disabilities or at high risk of developmental disabilities [16,17]. Moreover, qualitative research has been conducted on the experiences of mothers of children with developmental disabilities, but our literature search yielded limited results in terms of the distinct characteristics of premature infants [18].

Therefore, this in-depth study examined how Korean mo- thers of premature infants receiving continuous rehabilitation treatment due to a high risk of developmental disabilities or the diagnosis of developmental disabilities subjectively experienced their actual situation and context, as well as the type of difficulties that they experienced, through phenomenological qualitative research. Furthermore, this study may provide a basis for developing measures to provide support and resources to the homes of premature infants who need continuous rehabilitation treatment due to developmental disabilities or a high risk thereof. In addition, this study lays the foundation for the development of care programs to help the mothers and families of premature infants with developmental disabilities.

This study investigated the experiences of mothers with a premature infant receiving continuous rehabilitation treatment due to a high risk of developmental disabilities or having been diagnosed with developmental disabilities. The research question was 'What is the experience of a mother with a premature infant receiving rehabilitation treatment?'.

\section{METHODS}

\section{Research Design}

This study sought to obtain an in-depth understanding and detailed description of the experiences of mothers with premature infants receiving rehabilitation treatment by using a qualitative research design based on Colaizzi's phenomenological research method [19].

\section{Research Participants}

The research participants were mothers of premature infants receiving continuous rehabilitation treatment due to developmental disabilities or a high risk thereof in Seoul and Gyeonggi Province. In this study, participants were recruited using snowball sampling; a mother of a premature infant who was known to the researcher and already had a trusting relationship with the researcher introduced a participant, who then recommended acquaintances or other parents of infants receiving rehabilitation treatment at the same hospital; among these individuals, those who agreed to participate in this study were selected as research participants.

Specifically, mothers of premature infants who had received continuous rehabilitation treatment for at least 1 year, including during the research, were selected as research participants to obtain an in-depth understanding of the mothers' experiences. In order to obtain information on a variety of experiences, the participants were not specifically limited to the mothers of premature infants within a specific age group or 
who attended a particular type of rehabilitation center. The total number of participants was 12, and their general characteristics are shown in Table 1.

\section{Research Preparation}

For this study, I developed expertise in performing qualitative research by attending many qualitative research conferences and workshops, and I had previously conducted qualitative research using phenomenological research methods. Moreover, I worked as a nurse in the NICU at a uni- versity hospital for several years, and I met many mothers of premature infants after conducting home visits for the further assessment of discharged premature infants. Through these experiences, I became especially interested in premature infants with developmental disabilities or at a high risk of developmental disabilities and how their mothers experienced their own personal triumphs and tragedies during their children's rehabilitation treatment, and I came to understand the necessity of support and care both for premature infants and for their mothers.

Table 1. Demographic and Disease-related Characteristics of the Participants

$(N=12)$

\begin{tabular}{|c|c|c|c|c|c|c|c|c|c|c|c|c|c|}
\hline \multirow[b]{2}{*}{ No } & \multicolumn{7}{|c|}{ Mother } & \multicolumn{6}{|c|}{ Child } \\
\hline & $\begin{array}{l}\text { Age } \\
\text { (year) }\end{array}$ & $\begin{array}{l}\text { Marital } \\
\text { status }\end{array}$ & $\begin{array}{c}\text { Education } \\
\text { level }\end{array}$ & Religion & $\begin{array}{l}\text { Current } \\
\text { job status }\end{array}$ & $\begin{array}{l}\text { Monthly } \\
\text { income } \\
\text { (10,000 won) }\end{array}$ & WPP & $\begin{array}{l}\text { Birth } \\
\text { year }\end{array}$ & $\begin{array}{l}\text { GA } \\
\text { (week) }\end{array}$ & $\begin{array}{l}\text { Birth } \\
\text { weight } \\
\text { (g) }\end{array}$ & Diagnosis & $\begin{array}{c}\text { PRT } \\
\text { (month) }\end{array}$ & $\begin{array}{l}\text { Current rehabilitation } \\
\text { therapy and institution }\end{array}$ \\
\hline 1 & 38 & Married & $\begin{array}{l}\text { Graduate } \\
\text { school }\end{array}$ & Protestantism & Yes & 500 & No & 2013 & 27 & 1,100 & Brain lesion & 48 & $\begin{array}{l}\text { Exercise, occupational, } \\
\text { language, physical: } \\
\text { RH, center }\end{array}$ \\
\hline 2 & 37 & Married & High school & Buddhism & None & 300 & No & 2014 & 30 & 1,600 & Brain lesion & 48 & $\begin{array}{l}\text { Exercise, occupational, } \\
\text { language, physical, } \\
\text { hydrotherapy: } \\
\text { RH, UH, WC, center }\end{array}$ \\
\hline 3 & 36 & Married & University & None & None & 500 & Yes & 2013 & 32 & 1,800 & $\begin{array}{c}\text { Split } \\
\text { encephalopathy }\end{array}$ & 48 & $\begin{array}{c}\text { Occupational, language, } \\
\text { physical: } \\
\text { RH, UH, WC }\end{array}$ \\
\hline 4 & 41 & Married & University & Protestantism & None & 150 & No & 2008 & 26 & 907 & Brain lesion & 96 & $\begin{array}{l}\text { Occupational, language, } \\
\text { physical: } \\
\text { RH, UH, WC, center }\end{array}$ \\
\hline 5 & 40 & Married & University & Protestantism & None & 300 & No & 2014 & 28 & 1,050 & $\begin{array}{l}\text { Hydrocephalus, } \\
\text { Syncephaly }\end{array}$ & 36 & $\begin{array}{l}\text { Occupational, language, } \\
\text { physical: } \\
\text { RH, UH }\end{array}$ \\
\hline 6 & 30 & Married & University & Protestantism & None & 480 & No & 2016 & 26 & 1,010 & Brain hemorrhage & 5 & $\begin{array}{c}\text { Exercise, occupational: } \\
\text { RH }\end{array}$ \\
\hline 7 & 31 & Married & University & None & None & 200 & No & 2015 & 33 & 1,500 & $\begin{array}{l}\text { Cerebellum } \\
\text { malformation }\end{array}$ & 18 & $\begin{array}{c}\text { Occupational, language, } \\
\text { physical: } \\
\text { RH }\end{array}$ \\
\hline 8 & 35 & Married & University & None & None & 200 & Yes & 2014 & 25 & 940 & Brain lesion & 27 & $\begin{array}{c}\text { Occupational, language, } \\
\text { physical: } \\
\text { RH, WC, center }\end{array}$ \\
\hline 9 & 33 & Married & University & Protestantism & None & 200 & No & 2012 & 33 & 1,800 & PVL & 60 & $\begin{array}{l}\text { Occupational, language, } \\
\text { physical, electrotherapy, } \\
\text { hydrotherapy: } \\
\text { RH, center }\end{array}$ \\
\hline 10 & 31 & Married & University & Protestantism & None & 230 & No & 2012 & 27 & 1,040 & PVL & 48 & $\begin{array}{c}\text { Occupational, language, } \\
\text { physical: } \\
\text { RH, WC }\end{array}$ \\
\hline 11 & 39 & Married & High school & None & None & 400 & No & 2009 & 28 & 1,230 & Brain lesion & 96 & $\begin{array}{l}\text { Occupational, language, } \\
\text { physical: } \\
\text { RH, WC }\end{array}$ \\
\hline 12 & 30 & Married & University & None & None & 230 & No & 2010 & 28 & 1,070 & Brain lesion & 84 & $\begin{array}{c}\text { Occupational, language, } \\
\text { physical: } \\
\text { RH }\end{array}$ \\
\hline
\end{tabular}

WPP=Whether or not participants lived with parents; $G A=$ Gestational age; PRT=Period of rehabilitation therapy; PVL=Periventricular leukomalacia; $\mathrm{RH}=$ Rehabilitation hospital; $\mathrm{UH}=$ University affiliated hospital; $\mathrm{WC}=$ Welfare center. 


\section{Data Collection}

Data collection began in July 2017 and lasted through August 2017, and involved individual in-depth interviews with a simple questionnaire asking about the general characteristics of participants and open-ended questions. A single in-depth interview with each participant was conducted, lasting from an hour to an hour and 50 minutes. As a feature of participants who had to take care of their children, there were limitations to additional interviews. So the first round of interviews went on until no new topic came up. The interviews were conducted at places where participants felt at ease, such as a counseling center in the hospital, a hospital lounge, a coffee shop near the hospital, and a participant's home.

The primary question was "What kind of experiences did you have as a mother of a premature infant receiving rehabilitation treatment?". The following questions included: "How did you give birth?"; "How would you describe your thoughts or feelings after giving birth?"; "How did your life change after your child started rehabilitation treatment?"; "What is the hardest part of raising your child?"; "What have you learned from raising your child?"; "What was the most memorable experience of raising your child?"; and "What does your child mean to you?". During the interviews, the researcher listened carefully to the participants, tape-recorded everything, and downloaded the recording onto a computer, while keeping empathic neutrality. After each interview, the researcher recorded a written description of the responses and attitudes of the participant and the atmosphere of the interview in an interview log. Additionally, tape-recorded interviews were kept as a computer files, and transcript analysis was conducted by referring to the interview $\log$, which was recorded on the day of each interview. Interviews were done until no new data or topics were obtained from the interviews of new participants. Thus, after interviewing 12 participants, data collection was ceased.

\section{Data Analysis}

Data analysis was conducted using Colaizzi's method [19]. In stage 1, the researcher listened carefully to the tape-recorded interviews once again and read the transcripts of interviews thoroughly to reflect on the overall feeling of participants' experiences. In stage 2, the researcher reread the transcripts and 157 significant statements were extracted from all transcripts that contained passages relating to participants' experiences. In stage 3 , the statements derived from the relevant passages were formulated abstractly. In stage 4 , similar meanings were integrated and divided into 16 themes. In stage 5 , the themes were categorized into five clusters to show the nature and structure of the totality of experiences. In stage 6 , a participant confirmed that the described themes and clusters of themes corresponded to her experiences.

\section{Ethical Considerations}

Before proceeding with data collection, this study was approved by the Kangwon National University Institutional Review Board (IRB-2017-03-007-002). The researcher explained the purpose of the study and the interview process and informed participants that the interview would be tape-recorded and that the anonymously collected data would be used for research purposes only. In addition, participants were allowed to stop participating in the research whenever they wanted. Interviews were conducted after participants signed a written consent form, and they were provided the researcher's contact information. After the interviews, the researcher paid a transportation fee to the participants. The researcher carefully followed the terms of the participants' agreement. Moreover, serial numbers were given to the tape-recorded interviews and the transcripts, which were downloaded as computer files under the researcher's supervision.

\section{Validity of Research}

In order to ensure the validity of this study, it was conducted following Sandelowski's [20] criteria for evaluating qualitative research. First, regarding the optimization of credibility, participants were selected in a way such that they would be able to share various experiences of mothers with premature infants receiving rehabilitation treatment, data were collected through individual in-depth interviews that consisted of semi-structured, open-ended questions, and interviews were conducted until there were no new subjects in terms of mothers' experiences. In addition, the researcher was careful not to intervene with her own prejudice or bias during the interviews, which were tape-recorded without omission or errors, and participants reconfirmed any vague statements. The recorded data were manually transcribed and a participant confirmed the results of data analysis. Second, to increase fittingness, participants were selected in a way such that they would be able to share various experiences of mothers with premature infants receiving rehabilitation treatment, and the researcher identified the general characteristics of participants; furthermore, data were collected until there were no new subjects in terms of mothers' experiences. Third, to enhance auditability, data were analyzed using Colaizzi's [19] phenomenological data analysis process; hence, the analytical process of the researcher was traceable, participants confirmed the themes that were extracted from the data analy- 
sis results and clusters of themes, and the research results were cross-checked with the raw data. Fourth, to maximize confirmability, the results of the researcher's analysis used direct quotes from the participants. Furthermore, the results of the analysis were confirmed with a colleague by soliciting and receiving feedback from a nursing professor with expensive experience in qualitative research.

\section{RESULTS}

In this study, 157 significant statements were extracted from the raw data that were collected from 12 participants. From these statements, 16 themes were organized by formulating and categorizing statements with a similar meaning. Then, the themes drawn from the exhaustive description were integrated into five thematic clusters (Table 2).

\section{Regret and Guilt that Premature Birth led to Rehabilita - tion Therapy}

\section{1) Guilt for giving birth to a premature baby}

The participants recalled their experiences of having an unexpected premature birth. They expressed regret and guilt for the present condition of their premature infants, which they perceived to be their fault for not protecting the infants through a full-term pregnancy. Moreover, the participants blamed themselves for having a premature birth due to their lack of selfcare.
I felt sorry for my baby. It felt like my baby was born premature because I wasn't the right mother for this baby, and everything still seems to be my fault. I should have been on maternity leave. Then things wouldn't have turned out this way. I experienced a lot of regret and cried a lot. (Participant 2)

I just felt sorry. When I'm wearing clothes like this, I want to put my baby back inside my womb and give birth one more time. I am really sorry that my baby is unhealthy because of me. I just want to hold my baby longer in my womb and give birth again. (Participant 12)

\section{2) Regret for delays in rehabilitation treatment}

The participants assumed that their premature babies-who were born very small and early-would have developmental delays, but they were unaware of the option of rehabilitation treatment for their children. After receiving advice about rehabilitation treatment and noticing the improved condition of their children, the participants regretted the delay in treatment.

I thought all premature babies showed rigidity. No one told me about rehabilitation treatment for stiffness. I thought it would improve after some time. I never thought it was weird. Six months after discharge, I took my child to the hospital and the doctor told me to bring my baby to the rehabilitation department. It was the first time that we heard this bad news from a doctor, and we began rehabilitation treatment at that time. (Participant 3)

Table 2. Experiences of Mothers of Premature Infants Receiving Rehabilitative Therapy

\begin{tabular}{|c|c|}
\hline Theme & Thematic cluster \\
\hline $\begin{array}{l}\text { - Guilt for giving birth to a premature baby } \\
\text { - Regret for delays in rehabilitation treatment } \\
\text { - Feeling sorry about the impact of the schedule of rehabilitation therapy }\end{array}$ & $\begin{array}{l}\text { - Regret and guilt that premature birth led to } \\
\text { rehabilitation therapy }\end{array}$ \\
\hline $\begin{array}{l}\text { - Physical fatigue and financial burden of child care } \\
\text { - Feeling helpless at a situation where I can't take care of myself } \\
\text { - Non-stop rehabilitation therapy, with fear and anxiety about outcomes }\end{array}$ & - Burden of life in an endless tunnel \\
\hline $\begin{array}{l}\text { - Complaints about husbands who play a limited role } \\
\text { - Feeling sorry for not being able to love another child enough } \\
\text { - Building a wall with in-laws who do not understand } \\
\text { - Avoiding friends with healthy children } \\
\text { - Getting comfort and strength from other mothers in the same situation }\end{array}$ & $\begin{array}{l}\text { Change in personal relationships surrounding me } \\
\text { and my child }\end{array}$ \\
\hline $\begin{array}{l}\cdot \text { Hope for more rehabilitation therapy opportunities } \\
\cdot \text { Hope for systematic information to be provided }\end{array}$ & $\begin{array}{l}\text { - Desire to expand the rehabilitation of premature } \\
\text { infants }\end{array}$ \\
\hline
\end{tabular}




\section{3) Feeling sorry about the impact of the schedule of rehabilitation therapy}

The participants felt sorry for their children who started rehabilitation treatment according to the hospital's schedule after discharge, since the premature infants had been immediately faced with a life-or-death situation during intensive care treatment after birth. The participants' children had to adjust their lives to the treatment schedule rather than being able to do whatever they wanted. On the one hand, the participants were proud of their children for receiving and enduring the treatment, but on the other hand, they were sorry that the children had to adjust their lives to the schedule of rehabilitation treatment.

There is no specific time slot for my baby to get rehabilitation treatment. My baby and I go whenever there is a free spot in the hospital's schedule. I'm not complaining. It's just hard to work around the doctors' schedule since a baby needs to take a nap during the day. (Participant 3 )

My child cannot have fun, and needs to stay in the hospital for six hours at a time, even if he is sleepy or hungry. It is hard to watch my baby receiving rehabilitation treatment on a schedule. The treatment has been ongoing since birth. A baby needs to eat and sleep a lot, but mine needs treatment. It's really sad and hurts my heart. (Participant 11)

\section{Burden of Life in an Endless Tunnel}

\section{1) Physical fatigue and financial burden of child care}

The participants vividly described to the researcher how they suffered from physical exhaustion while taking care of their children who were growing, but still had difficulties walking. In particular, the participants struggled to raise their children who were getting older. In particular, the mothers had to deal with everything regarding the children by themselves, without discontinuing rehabilitation treatment or leaving their children with someone else. Furthermore, the participants were financially burdened by the cost of rehabilitation treatment for their children. Fortunately, the mothers with health insurance coverage had less burden due to treatment, but they still reported difficulties in paying for the additional costs of treatment at private rehabilitation centers.

The most difficult thing was that I was having health issues. My child was growing up, but I still had to carry my baby and it killed my knees. Last year, I had a knee replacement due to damaged cartilage. (Participant 2)

I thought that it would be doable for my child to get rehabilitation treatment since I was covered by health insu- rance. But now it's different. If I lose my insurance, I have to cut down on treatment considerably. Of course, rehabilitation treatment is physically and emotionally hard. However, it's also economically difficult, which it makes everything harder. (Participant 3 )

Listening to other mothers saying, "Oh, that center has a good treatment program." or "The center is a good facility for rehabilitation treatment." made me try out those places. At the time, all I wanted was for my child to recover, but treatment cost a lot-more than I expected-and as the treatments became more frequent, I had financial difficulties. (Participant 4)

\section{2) Feeling helplessness in a situation where I can't take care of myself}

The participants talked about their lives, which changed completely after childbirth. From hospitalization in the NICU to the present with continuous rehabilitation treatment, the participants' lives have been entirely focused on their children, with no personal time. Thus, they were unable to take care of themselves. Such a life caused participants to feel intense helplessness and unrelieved stress.

My life completely changes after childbirth. From that moment, I do not exist. There's no life, thoughts, or things to do for me. (Participant 1)

Just going back and forth between the hospital and home? No time for myself. I am stuck with my child. Actually, if my child gets better, I would keep on doing it. Nothing. There is no life for me. I can't live the way I used to before birth. (Participant 6)

\section{3) Non-stop rehabilitation therapy, with fear and anxiety about outcomes}

At the beginning of rehabilitation treatment, the participants visited the hospital almost every day, except for the weekend. During the treatment period, they felt uncomfortable stopping the treatment because they were afraid that their children's condition might revert to how it was before treatment. In addition, they stated that they felt fear and anxiety about their children's development and health since they were born premature. In particular, their fear and anxiety grew as time passed in the rehabilitation program.

The treatment began in January 2014 and has continued since. It has never stopped except for when my child was hospitalized for pneumonia or bronchitis. You can see the effects if you take a break from treatment. Usually, if we take a break from treatment for even three consecutive days-from Saturday to Monday-my child's 
body becomes severely rigid and the muscles remain tightened, even after receiving treatment for 30 minutes. The treatment takes longer to loosen the body. We never stopped treatment except for hospitalization, not even for a week. (Participant 1)

I am always anxious. Every time, I am anxious that my child will lag behind other children. My child was born too small. Even if the rehabilitation treatment ends here, there's no guarantee that my child will be healthy. You know, the diagnosis from the hospital. I worry that my child will go through hard times in terms of development or everyday life. (Participant 6)

\section{Changes in Personal Relationships Surrounding Me and My Child}

\section{1) Complaints about husbands who play a limited role}

Most participants described enduring hard times with support and cooperation from their husbands, since a couple must take care of their premature child together. However, when it came to taking care of a premature child receiving rehabilitation treatment, the participants acknowledged the limited role of their husbands. Despite their dissatisfaction and unresolved conflicts with their husbands, the participants eventually accepted that caring for their premature child would be their responsibility.

My husband should understand me and our child more than anyone, because hospital treatment is not the whole thing. The treatment continues even at home. So, I mostly talk with my husband. (Participant 11)

My husband stopped taking care of our child, so he has no idea what to do with him. When he occasionally tries to bathe the baby, he yells at hin. (Participant 4)

\section{2) Feeling sorry for not being able to love another child enough}

As the participants' lives were focused on the unhealthy premature child, they suffered from the fact that they were unable to take proper care of their other children, who they also felt sorry for. Some participants expressed difficulty in building a relationship with their other children due to conflict or a failure to develop attachment. Furthermore, the participants deeply regretted requiring the other children to do everything by themselves at a young age.

Whatever I do, my number one priority is my son. Now the other children had accepted it, but they still complain about it. I thought I was loving them equally, but I can't help that he is the one that I care the most about. I now know that you cannot take care of them equally. (Partici- pant 3)

When I was hugging and playing with my oldest child, the younger one was crying in the corner. I asked him, "Why are you crying?". Then, she told me that I liked her brother too much so there was no space for her to be. My heart fell. I realized that I should not do that. I am doing the best I can but my daughter doesn't see it that way. So, wow. It struck me and I realized that I hadn't been handling it right. (Participant 9)

\section{3) Building a wall with in-laws who do not understand}

Most participants were not appreciated by their parents-inlaw for the hard work of rehabilitation treatment, and they blamed themselves for the premature birth. Furthermore, the participants built a wall around their parents-in-law who worried about their child, the husband, and put him before their grandchild.

I try my best to take care of my child. But my mother-in-law doesn't care and it was really hard for me. At first, I thought that she was inconsiderate and I loathed her for being such a mean person. Now, I listen and forget. I honestly couldn't care less. (Participant 2)

All parents care more about their own child rather than a grandchild since they suffer more from the troubles of their own child. (Participant 10)

\section{4) Avoiding friends with healthy children}

As time passed, the participants became frustrated watching their children struggling to achieve developmental milestones, and compared their children with the healthy children of relatives or friends. Eventually, the participants became estranged from friends who could not understand their lives in depth.

If a relative or friend gives birth, here's what I think: 'I wish my child would move one step forward, whether crawling or sitting.' . After a year, a newborn begins to walk, but my child still cannot do anything. Honestly, seeing it makes me uncomfortable, even though the baby is the child of a relative or friend of mine. (Participant 3 )

I alienated myself from my friends, even though they told me that they understood the difference between raising a healthy and an unhealthy child. In the past, I used to meet with them and talk about it, but now I just distance myself from my friends. (Participant 10)

\section{5) Getting comfort and strength from other mothers in the same situation}

The participants gained comfort and strength by meeting 
and sharing their experiences with other mothers from the same rehabilitation center who were in the same situation. In particular, they shared similar experiences of premature birth and became a major source of information for each other. The mothers shared a wide range of experiences, including trivial things in the hospital, information related to treatment, and difficulties in dealing with family conflict, and this encouraged the participants to a great extent.

When I go to a hospital or a social welfare center, I am consoled by talking with mothers who have sick children. We have common interests, so talking to each other is comforting and it gives me strength to endure the hardships. Meeting other moms helped me to learn new information and to realize that my child is not the only one, but there are also other children with the same condition. (Participant 3)

\section{Meaning of New Life through My Child}

\section{1) Thankfulness for living with a child who was in a life-and- death situation}

While taking care of a child receiving rehabilitation treatment, the participants were happy and delighted to notice small changes or developments that they had taken for granted in the past. Specifically, they recalled the situation at the time of the premature birth. Despite day-to-day worries about the risk of impairment that the child faced, they soon became thankful that the child was alive. By recalling the past, they also appreciated being with the child in the present. In addition, they started to seek out other children with similar difficulties.

As my son slowly achieves something that he couldn't do in the past due to his condition, we're happy to see his progress. If he accomplishes something, even though it takes a lot of effort, it's delightful in its own way. (Participant 3)

At first, I thought my baby was not going to make it, so I prayed for her to live. At the time, there was not much information on premature infants. Even if she stays in bed forever, I wanted her to live. Blindness or liver transplant, I didn't care. I just wanted her to breathe. Every time, I heard bad news from the hospital that my baby might die. After discharge, I was so excited to see her in my arms. (Participant 12)

Unhealthy children are now more noticeable than healthy ones, ever since my son got sick. In the past, I used to avoid seeing children with disabilities. I wished that they would be nowhere near me. Now, I approach them to show support by holding their hand.(Participant 12)

\section{2) Recognizing my child as the reason for my being}

In a way, the children were themselves mothers for the participants, and the children meant more to them than just being special children needing care. They were the purpose of the participants' lives. The participants stated that their children supported their lives and life without them would be unthinkable.

When I saw my baby, I thought the baby was just me. A child is the object of love to whom I can give everything. If a child is sick. I am sick too. If a child struggles, I struggle too. A child is a child, nothing more or less. But my baby is just me. (Participant 1 )

First of all, I have to live. I need to live because of my child. I don't want to be a burden to my child. I have to live so that I can take care of my child. I believe that I have to be healthy to do so. My purpose in life. (Participant 5)

\section{3) Waiting for the development of a child to progress gradually}

The most special memory for the participants was when their children achieved developmental steps that were expected and planned. As the participants recalled such experiences, they described them as the most pleasant and happiest moments of their lives. While waiting for the gradual development of the child, the participants had the goal of raising a self-reliant child after they walked and grew up by continuing the current rehabilitation treatment, despite the gradual pace of progress. They continued to wait. Although they could not see the light at the end of the tunnel, they hoped to reach the end of the tunnel while waiting for the end of treatment.

Now that I look back, it has gone so fast. In the future, our goal is to teach our child to become a self-reliant adult. I am uncertain. A decade from now will be a more important period for the child than the past years. Even though we are having hard times now, I believe that we will get better as long as we have this goal. (Participant 4)

I am waiting for my child to begin speaking; 'Wouldn't it be much better if he could speak?'. I believe it will happen someday. Walking started with just a step or two, but now he can walk from here to there, even though he falls down a few times. I thought, 'By the end of summer, someday, he will walk.'. The progress is slow by my standards but it's progress. But when you think it's slow, there's a surprise; he makes a major step forward. Then, I hope for him to walk by the end of the year. Every time, I try to look for the bright side. (Participant 7)

I feel like I'm in a long tunnel. A tunnel without an end? When you see it, it's dark. I can't see anything. The end of the tunnel will come when my child grows up and 
I hear from the hospital that he no longer needs to get rehabilitation treatment. If it happens, that's the end. I just want to get out the tunnel soon. (Participant 6)

\section{Desire to Expand the Rehabilitation of Premature Infants}

\section{1) Hope for more rehabilitation therapy opportunities}

Participants were disappointed with the lack of rehabilitation treatment centers for premature infants and the limited opportunities for treatment. In addition, they hoped that their children would receive enough treatment by increasing the number of treatment centers and treatment opportunities in the future.

I hope that more pediatric rehabilitation hospitals are opened where premature children can get treatment. There are only a few pediatric rehabilitation centers. Most of the ones that do exist are located in large or university hospitals. There are no private hospitals for treatment. Moreover, I hope that there will be some kind of financial support program for families with a premature child, since rehabilitation treatment is too expensive. Plus, I wish that treatment centers would be located close to where I live. (Participant 2)

I hope that there will be a lot of treatment centers and treatment opportunities. I wish for this type of treatment or hospital to become more common in the future. To be honest, most rehabilitation treatment centers are all bunched together in Seoul. All the patients living in other areas need to go Seoul for hospitalization. The government should take this situation into consideration. (Participant 12)

\section{2) Hope for systematic information to be provided}

Participants recalled the time from the moment of premature birth to the beginning of rehabilitation as having been helter-skelter, without precise and reliable information. They hoped for the implementation of a social system that would convey organized and exact information on rehabilitation treatment, as well as various support programs, to the parents.

Mothers receive education from the hospital after premature birth or the hospitalization of a premature child. I wish there would be a basic education program-even if simple and formal-for mothers with premature children. Taking care of a premature child requires special care, a lot of supervision, and immediate treatment, yet mothers have no source of information on these issues. It takes a lot of time and effort to find detailed information on rehabilitation treatment hospitals or the type of necessary treatment for my child. If you don't know, then you have no idea. It is hard for mothers to look up the information online; for example, it is difficult to find website information, government support-including how to get financial support from the government-or how to rent medical engineering equipment that is appropriate for one's child. (Participant 1)

\section{DISCUSSION}

In this study, 16 themes were extracted from 157 significant statements, and the themes were ultimately categorized into five clusters.

First, participants blamed themselves for the condition of their child who is currently receiving rehabilitation treatment due to an unexpected premature birth, and they regretted delays in rehabilitation treatment, even though they assumed that the premature child would develop slowly, in the cluster "Regret and guilt that premature birth led to rehabilitation therapy". In addition, they felt sorry that the child's life had to be organized around the hospital's schedule due to the rehabilitation treatment, since the child had been treated in the NICU immediately after the premature birth. In this cluster of themes, the participants expressed deep-rooted feelings of guilt due to the premature birth; as such, the experience of mothers of premature infants is distinct from the experience of parents who have a child with a disability from another chronic illness. Even once a significant amount of time passed after the premature birth, participants continued to have negative feelings towards their premature infants at high risk of disability. In addition, previous studies [12-14] have reported that the mothers of premature infants with disabilities were at higher risk of depression than the mothers of children without disabilities. This finding should be understood in terms of guilt regarding the premature birth. Furthermore, it would help to reduce mothers' negative feelings by providing them with support for starting rehabilitation treatment of premature children at the right time by means of thorough education about the development of premature infants and rehabilitation treatment. In addition, medical staff should acknowledge that premature infants who receive immediate intensive care treatment after birth are likely to enter another treatment process after discharge. Thus, careful consideration and understanding of premature infants and their mothers are necessary.

Second, in the thematic cluster of "Burden of life in an endless tunnel", participants described their physical burden and the financial burden of treatment while taking care of a child receiving rehabilitation treatment. Moreover, they were unable to take breaks from treatment due to fear and anxiety about the child's development and health condition. The mo- 
ther of a premature child may have no time to take care of her own health after becoming absorbed in the child's intensive care treatment immediately after birth. In these circumstances, participants experienced severe helplessness and stress. The disabilities of a premature infant increase parenting-related physical and economic stress, threatening the mother's mental health status [13]. Thus, in order to reduce postpartum depression and the parenting-related stress of mothers of premature infants, and to develop programs that enhance the role of parents $[9,21]$, the target participants of the program should be considered in detail, with attention paid to factors such as the presence or absence of disabilities in their premature infants and various types of disabilities. Moreover, various forms of support should be provided to improve the psychological condition of mothers of premature infants, as well as to alleviate their financial and psychological burdens. In Korea, a policy supporting the treatment cost of premature infants was initiated in 2,000 and has since been administered on a national level, but support for the developmental process of premature infants after discharge is lacking in comparison to foreign countries [22]. Based on this study, the developmental process of premature infants after discharge should be considered from a long-term perspective, and further research is needed to identify support measures.

Third, in the thematic cluster "Changes in personal relationships surrounding me and my child", participants experienced changes in their relationships with their husbands, other children, parents-in-law, others, and support groups. The participants relied on their husbands as the other parent of the premature infant and their closest partner, but they were dissatisfied with the limited role played by their husbands. Husbands' direct participation in parenting and caring, as well as measures that help promote understanding between husbands and wives, are required to foster a positive and supportive environment in families with a premature infant receiving rehabilitation treatment. However, to help fathers of a premature infant at high risk, who are in the midst of the domestic crisis caused by the premature birth and face difficulties preserving the trust and patience of the child [23], it is necessary to understand their journey to become fathers of premature children receiving rehabilitation treatment. Furthermore, participants had other children in a similar age group (i.e., slightly older or younger) as the premature child who was receiving rehabilitation treatment. They felt sorry for the siblings of the premature infants. The participants thought that behavioral problems of the siblings were caused by the participants being unable to give their full attention and love to them since they had to concentrate on taking care of the premature child. The study of Hartling et al. [24] suggested that intervention programs for siblings of children with a chronic illness or disabilities may be efficacious, since those siblings are at high risk of problematic emotional and behavioral outcomes. Based on the findings of this study, it could be feasible to develop an intervention program to improve the relationships between siblings of a premature infant receiving rehabilitation treatment and their mother. The relationship between participants and parents-in-law should be understood in the sociocultural context of patriarchal Confucian culture in Korea [25], and strategies should be developed to help mothers reestablish their relationships with husbands and parentsin-law to cope with the situation without blaming themselves or becoming frustrated. Participants' experiences of changes in family and social relationships suggest the importance of support from other mothers of premature infants in addition to family, since those relationships function as a social support system [26]. In the development of an intervention program, an effective content structure could be formulated by conducting support group meetings.

Fourth, in the thematic cluster "Meaning of new life through my child", participants expressed appreciation that they could be with their child in the present moment when they recalled the premature birth; even though the premature children were at risk of developing disabilities in the life-and-death situation of premature birth, they were born alive in the mothers' arms. Moreover, the participants were delighted to see subtle changes and developments, and they sought out other premature children and their mothers who are experiencing similar difficulties. Additionally, they acknowledged that their children were the reason and purpose of their lives. In comparison to the mothers of full-term children, the mothers of premature children tend to have more negative feelings towards their children and poorer mental health status. However, personal growth was noticeable after a year according to the results of previous studies [27]. Thus, the participants of this study likewise had the opportunity to grow by developing the power of endurance through the process of finding a new meaning of life.

Lastly, participants hoped to have more rehabilitation treatment opportunities for premature infants, and they wished to have more organized and detailed information on the development and treatment of children in the thematic cluster "Desire to expand the rehabilitation of premature infants". Although the policy of premature infant support is expanding in Korea, practical and sufficient health and medical care services are still not provided with regard to the need for continuous rehabilitation treatment. Thus, a service intervention would be in the national interest, and such a program should be put in place for families and their premature infants who require continuous rehabilitation treatment by providing information on rehabilitation treatment support and promoting 
such programs $[22,28]$.

This qualitative study explored the experiences of mothers of premature infants receiving rehabilitation therapy in various circumstances in detail, rather than providing generalized results. In future studies, mothers' experiences could be investigated in terms of the socioeconomic environment of families of premature infants, the characteristics of the health of premature infants, or the rehabilitation period.

\section{CONCLUSION}

In this study, phenomenological qualitative research was conducted to examine the experiences of mothers of premature infants receiving rehabilitation treatment through individual in-depth interviews of 12 mothers whose premature infants had received continuous rehabilitation treatment for more than a year. A total of 16 themes were formulated from the 157 significant statements, and five clusters of themes emerged: regret and guilt that premature birth led to rehabilitation therapy; burden of life in an endless tunnel; changes in personal relationships surrounding me and my child; meaning of new life through my child; and desire to expand the rehabilitation of premature infants. The results of this study are significant in that they provide basic data for the development of care programs to support premature infants who require continuous rehabilitation treatment and their families.

\section{Conflict of interest}

No potential or any existing conflict of interest relevant to this article was reported.

\section{REFERENCES}

1. Statistics Korea. 2016 Annual report on live births and deaths statistics [Internet]. Daejeon: Statistics Korea; 2017 [cited 2018 February 10]. Available from:

http://kosis.kr/publication/publicationThema.do.

2. Kim YD. Impact of the designated regional neonatal intensive care unit on neonatal mortality and morbidity in the Jeju area. Neonatal Medicine. 2014;21(1):10-17.

https://doi.org/10.5385/nm.2014.21.1.10

3. Hahn WH, Chang JY, Chang YS, Shim KS, Bae CW. Recent trends in neonatal mortality in very low birth weight Korean infants: In comparison with Japan and the USA. Journal of Korean Medical Science. 2011;26(4):467-473.

https://doi.org/10.3346/jkms.2011.26.4.467

4. Bos AF, Roze E. Neurodevelopmental outcome in preterm infants. Developmental Medicine \& Child Neurology. 2011;53(s4):35-39. https://doi.org/10.1111/j.1469-8749.2011.04062.x
5. Terrien Church P, Luther M, Asztalos E. The perfect storm: The high prevalence low severity outcomes of the preterm survivors. Current Pediatric Reviews. 2012;8(2):142-151. https://doi.org/10.2174/157339612800681325

6. Cheon MK, Yum SK, Moon CJ, Youn YA, Kim SY, Sung IK. Risk factors for severity of intraventricular hemorrhage in very low birth weight infants and neurodevelopmental outcomes. Korean Journal of Perinatology. 2014;25(4);266-275. https://doi.org/10.14734/kjp.2014.25.4.266

7. Vohr BR, Wright LL, Poole WK, McDonald SA. Neurodevelopmental outcomes of extremely low birth weight infants $<32$ weeks' gestation between 1993 and 1998. Pediatrics. 2005;116(3):635-643. https://doi.org/10.1542/peds.2004-2247

8. Ahn YM. Rehabilitation of premature infants. Korean Journal of Nursing Query. 1998;7(2):33-49.

9. Kim MH, Ji ES. Effects of a hospital based follow-up program for mothers with very low birth weight infants. Journal of Korean Academy of Nursing. 2016;46(1):79-89.

https://doi.org/10.4040/jkan.2016.46.1.79

10. Bang KS, Kang HJ, Kwon MK. Relations of postpartum depression with socio-demographic and clinical characteristics of preterm infants and mothers. Child Health Nursing Research. 2015;21(1): 1-10. https://doi.org/10.4094/chnr.2015.21.1.1

11. Hwang HS, Kim HS, Yoo IY, Shin HS. Parenting stress in mothers of premature infants. Child Health Nursing Research. 2013;19(1): 39-48. https://doi.org/10.4094/chnr.2013.19.1.39

12. Treyvaud K, Doyle LW, Lee KJ, Roberts G, Cheong JLY, Inder TE, et al. Family functioning, burden and parenting stress 2 years after very preterm birth. Early Human Development. 2011;87(6):427-431. https://doi.org/10.1016/j.earlhumdev.2011.03.008

13. Rhee CW, Kim YH. Impact of preterm infants' disability on maternal depression: The mediating effect of parenting stress. Social Science Research Review. 2013;29(2):51-75.

14. An YH. Health status, factors impacting health of mothers of children with and without disabilities [master's thesis]. Seoul: Seoul National University; 2017. p. 1-89.

15. Lemos RA, Veríssimo MDLÓR. Functional development of preterm infants: An integrative literature review. Fisioterapia em Movimento. 2016;29(3):623-633.

https://doi.org/10.1590/1980-5918.029.003.AO20

16. Chon MY, Ji ES, Lee SH. Mothers' parenting experience of premature infants: Q methodological approach. Journal of Korean Academy of Nursing. 2013;43(6):704-713. https://doi.org/10.4040/jkan.2013.43.6.704

17. Park HS, Rhee CW. Post-discharge adjustment of families with pre-term infants. Journal of the Korean Society of Child Welfare. 2007;24:151-175.

18. Kim JS. A qualitative meta-synthesis study on caregiving experience among Korean mothers of developmentally disabled children. The Korean Journal of Counseling and Psychotherapy. 2015; 
27(2):463-492.

19. Colaizzi PF. Psychological research as the phenomenologist views it. 1st ed. New York: Oxford University Press; 1978. p. 48-71.

20. Sandelowski M. The problem of rigor in qualitative research. Advances in Nursing Science. 1986;8(3):27-37.

https://doi.org/10.1097/00012272-198604000-00005

21. Kim ES, Kim EY, Lee JY, Kim JK, Lee HJ, Lee SH, et al. The effects of supportive nursing management on postpartum depression of mothers with premature infants. Journal of Korean Clinical Nursing Research. 2009;15(3):157-170.

22. Lee Y. A comparative study on the support policy for prematurity in some OECD countries. Health and Social Welfare Review. 2016; 36(4):63-96. https://doi.org/10.15709/hswr.2016.36.4.63

23. Park JE, Lee BS. Experience of becoming a father of a high risk premature infant. Journal of Korean Academy of Nursing. 2017;47(2): 277-288. https://doi.org/10.4040/jkan.2017.47.2.277

24. Hartling L, Milne A, Tjosvold L, Wrightson D, Gallivan J, Newton AS. A systematic review of interventions to support siblings of children with chronic illness or disability. Journal of Paediatrics and Child Health. 2014;50(10):E26-E38.

https://doi.org/10.1111/j.1440-1754.2010.01771.x

25. Huang YP, Kellett UM, St John W. Cerebral palsy: Experiences of mothers after learning their child's diagnosis. Journal of Advanced Nursing. 2010;66(6):1213-1221.

https://doi.org/10.1111/j.1365-2648.2010.05270.x

26. Lee SNC, Long A, Boore J. Taiwanese women's experiences of becoming a mother to a very-low-birth-weight preterm infant: A grounded theory study. International Journal of Nursing Studies. 2009;46(3):326-336.

https://doi.org/10.1016/j.ijnurstu.2008.10.004

27. Taubman-Ben-Ari O, Findler L, Kuint J. Personal growth in the wake of stress: The case of mothers of preterm twins. The Journal of Psychology. 2010;144(2):185-204.

https://doi.org/10.1080/00223980903472268

28. Chang YS. Future of neonatology in Korea: The way forward. Journal of the Korean Medical Association. 2016;59(7):506-513. https://doi.org/10.5124/jkma.2016.59.7.506 